\title{
Community Perception on Lake Victoria Basin Resources Degradation: Implications to Sustainable Management
}

\author{
Albino J. M. Tenge ${ }^{1}$, Aloys N. Mvuma ${ }^{1}$, Samuel B. Baker ${ }^{2}$, Hector J. Mongi ${ }^{1}$, Jonathan Mwakijele ${ }^{3} \&$ Maria C. \\ Gabriel $^{1}$ \\ ${ }^{1}$ The University of Dodoma, Dodoma, Tanzania \\ ${ }^{2}$ Busitema University, Tororo, Uganda \\ ${ }^{3}$ Kigali Institute of Science and Technology, Rwanda \\ Correspondence: Albino J. M. Tenge, The University of Dodoma, P.O. Box 395, Dodoma, Tanzania. E-mail: \\ ajtenge@gmail.com; albino.tenge@udom.ac.tz
}

Received: November 4, 2014 Accepted: November 10, 2014 Online Published: March 30, 2015

doi:10.5539/jsd.v8n2p14

URL: http://dx.doi.org/10.5539/jsd.v8n2p14

\begin{abstract}
Degradation of Lake Victoria Basin (LVB) resources due to deforestation, illegal fishing and unsustainable farming practices is among the major challenge to the natural resources managers and the livelihood of surrounding communities. Several measures have been proposed to mitigate the situation. These measures range from policies, laws, regulations to technical options. Despite these efforts, adherence to these regulations and adoption of the proposed technologies is low. Among the factors that can influence household adoption of a particular technology is perception of the problem and the technology itself. This has not been thoroughly investigated and integrated in development and promotion of mitigation options. This research assessed the local community perception on the LVB resources, levels of degradation and the causes. The research was done in selected sites within LVB in Tanzania, Uganda and Rwanda. Data was collected through questionnaire interviews and focused group discussion to 334 respondents. Collected data was descriptively analyzed using means, frequencies, percentages and ranking. Results indicate that majority of community members perceive LVB resources to be currently more degraded than past twenty years. However, specific types of resources and levels of degradation do differ between countries. Degradation factors are personal, administrative, technical and policy related. Lack of alternatives is among the major driving forces to degradation activities. It is recommended that intervention efforts to reverse degradation situation need to consider local community perception and be of multiple nature to address technical, administrative and policy issues.
\end{abstract}

Keywords: adoption, Lake Victoria Basin, perception, resource degradation

\section{Introduction}

\subsection{Background Information}

Lake Victoria Basin (LVB) covering Tanzania, Uganda, Kenya, Rwanda and Burundi is an important source of livelihood for about 30 million people which is about $25 \%$ of the all population of East Africa. The basin provides resources for fishing, agriculture, forestry, water transport and other economic activities important not only to the community within the basin but also to the countries covered by the basin. Degradation of the LVB resources has therefore great consequences and is of major concern to natural resources managers and politicians.

Despite its importance, resources degradation in the LVB is continuing at a rate that threatens its sustainability; deforestation, illegal fishing and unsustainable agriculture being the major causes. The degradation of the water resources in LVB is evidenced by water pollution, eutrophication and siltation. The situation is likely to worsen by the impacts of climate change which is likely to increase the temperature and affect rainfall distribution making some parts drier than used to be (Intergovernmental Panel on Climate Change (IPCC), 2010).

Various efforts have been made by both government and nongovernmental organization at regional and national levels to ensure sustainable utilization of the LVB resources (Lake Victoria Basin Commission (LVBC), 2010). These efforts include formulation of policies, regulation and laws, development and promotion of technological options (LVBC, 2010). Despite these efforts adherence to the laws, regulations and adoption of proposed 
technologies for sustainable utilization of the LVB resources is low. Household's decision to adopt a particular technology depends on the number of factors. Among the factors is perception of the problem and the technology (Bagheri et al., 2008; DeGraff et al., 2008). Experiences from other studies also indicate that often conflicts over resource uses arose from differences in perceived benefits by local communities and priority management objectives (Roe, Nelson \& Sandbook, 2009). Limited understanding of the local community perception of the LVB resources in development and implementation of these measures can be contributing to the limited success of interventions to ensure sustainable utilization of LVB resources. Perception refers to the personal understanding of the phenomena, causes and its effects. This understanding influences necessary actions to be taken by an individual, group or a community plus its continued engagement (Bagheri et al., 2008). However, perception of the same phenomena can be different between and within the community depending on the cultural and other demographic characteristics.

Understanding the local community perception will make intervention efforts participatory and integrative; hence increase levels of adoption of technologies and adherence to regulations and laws for sustainable utilization of LVB resources. This paper analyses local community perception of the LVB resources, degradation levels, causes and implication to the sustainable management.

\subsection{Theoretical and Historical Context of the Study}

\subsubsection{Theoretical Context}

This study is based on the conceptual foundation on common property resources and their governance that some resources have traditionally been managed collectively or communally rather than individually, because they are subject to shared uses and it would be costly to individualize the resource. At the same time if such resources are left entirely ungoverned then the resource will be subject to depletion through the tragedy of common scenario whereby all users compete to access and utilize the resource (Gordon, 1954; Hardin, 1969; Agrawal \& Gibson, 1999). It is therefore, necessary that sustainable natural resource management and governance are characterized by community developing and agreeing to shared rules that limit and regulate resource uses. Adherence to these shared rules can be increased if community perceived benefits from natural resources surrounding them are understood and taken into consideration.

\subsubsection{Historical Context}

Before 1980s many Scholars assumed that local communities who are users of the natural resources could not organize themselves for effective management of their surrounding resources (Cox, Arnold \& Villamaytonias, 2010). As results many recommended approaches to manage natural resources, imposed state or private control, with little recognition of the people living closest to the resources (Hardin, 1968; Wood, 2008). Natural resources management policies during colonial era in Africa were mainly for extending colonial political control. The approach in natural resources conservation was that of setting aside some areas as reserves for human enjoyment and fulfillment. Ownership of the land resources was gradually transferred away from traditional local authorities to the state. Resources such as wildlife were progressively placed under central regulatory authority, with the rights of local people to utilize resources alienated over time (Roe et al., 2009).

After independency of most African countries in 1960s, many maintained the centralized political economic institutions which favored state direction of the economy and ownership of valuable resources (Van de Walle, 2001). Many approaches in conservation of natural resources were not successfully because of the little recognition of the local community roles and attachment to the natural resources (Tenge, De Graaff \& Hella, 2004). As a result more degradation of natural resources and conflicts were observed.

Failure of the state centered management of natural resources led to a paradigm shift in natural resource management towards approaches in which local people could play a more active role (Shackleton, Campbell, Wollenberg \& Edmund, 2002; Roe et al., 2009). Development theories that are oriented to rural development began to emphasize decentralization and local development (Chambers, 1987). The concept that local people may have an active role to play in management of their resources gained importance. This concept has led to several approaches trying to involve the local people. Among these approaches include Community Based Natural Resources Management (Wood, 2008), Community Based Natural Resources Management (CBNRM) approach aims at incorporating local communities into guardianship of their immediate environment in an attempt to meet ecological and social goals on both local, national and global scales (Agrawal \& Gibson, 1999). Roe et al., (2009) defines CBNRM as the management of resources such as land, forests, wildlife and water by collective local institutions for local benefits.

Different forms of CBNRM have been implemented in various countries including South Africa, Ghana, Kenya 
and Mexico (Shackleton et al., 2002; Berkes, 2004; Wood, 2008; Goman, Mahay, Mbilinyi, Dietrich \& Lischeid, 2009; Cox et al., 2010). There has been varying levels of success depending on local, national and global context within which the approach is applied. Among the factors for success were consideration of community needs, priorities, believes and their expectations (DeGeorges \& Reilly, 2009).

\section{Methodology}

\subsection{Selection of the Research Sites}

This research was conducted in Tanzania, Rwanda and Uganda. These are among the countries of East Africa surrounding the Lake Victoria. Specific sites in Tanzania were Mwanza, Kagera and Mara regions. Sites in Uganda were Buikwe and Mayuge districts. Sites in Rwanda were Kirehe, Kayonza, Bugesera districts in Eastern Province, Musanze district in Northern Province and Gisagara district in Southern province. These sites were selected based on the extent of water resources management challenges, community willingness to participate and on accessibility of the areas.

\subsection{Sample Selection and Sampling Procedure}

Two categories of respondents were involved in this research. The first category was key informants from different organizations dealing with LVB water resources management in the study areas. Key informant category included policy makers, administrators and professionals related to governance and sustainable utilization of LVB water resources. Key informants were purposefully selected based on their knowledge, experience and roles in LVB water resources management. A total of 88 key informants were involved in the study. Out of these, 56 were from Tanzania, 30 from Uganda and 2 from Rwanda. Diversity of information required in relation to LVB resources management guided the category and number of key informants to be involved in the study. The second categories of respondents were representatives of community members in the study areas. These were randomly selected making a total of 334; Out of these, 221 were from Tanzania, 59 from Uganda and 54 from Rwanda. Sampling frames for community members were obtained from the respective local government offices. The list of households from government offices was verified for updates and information for exclusion and inclusion in the sample. It was observed that the local government offices had update lists of households but missed some information for exclusion and inclusion in the sample. Corrections were made by obtaining all necessary information before establishment of the eventual sampling frame. Sample size from Tanzania was relatively large compared to other sites in Rwanda and Uganda because of the proportion of the population surrounded by LVB. However, the use of diverse methods of data collection and checks for saturation ensured that all important data/information was collected from all sites regardless of the sample size. This is scientific acceptable for a research that combines qualitative and quantitative approaches (Ritchie \& Lewis, 2003).

\subsection{Data Collection}

Structured interviews using pre-designed questionnaire were used to collect data from key informants and community member's representatives. Different sets of questionnaire were used to each category of respondents. The questionnaire for the interviews was designed consisting both open and close ended questions. Likert Scale questions were also included to measure perceptions and attitudes of respondents towards various issues related to water resources in LVB (Churchill, 1973; Lundstrom \& Lamont, 1976; Lancaster, 2005). Prior to the administration of questionnaires they were pretested to few respondents in Mwanza, Tanzania. This pre-testing served the purpose to check for reliability and validity of the information to be collected. It also served to estimate the time to be taken for the interview. Necessary corrections were made after pre-testing. The questionnaire was researcher administered with the assistance by trained research assistants. Focused Group Discussion (FGD) was used to complement and collect additional data. The two methods not only complemented each other but also used as a triangulation to check the validity and reliability of the collected data. Secondary data from scientific reports, maps and statistical abstracts were also used as addition sources of information. The type of data collected includes personal characteristics, resources availability and uses, local community understanding and perceptions on LVB resources, degradation levels, causes and effects.

\subsection{Data Analysis}

Collected data was processed and analysed using the Statistical Package for Social Sciences (SPSS) and Excel computer programs (Norusis, 1990, Field, 2005; Bowerman, O'Connell \& Murphree, 2011). Data was analysed to answer the following research questions (i) what are the socio-economic characteristics of local communities that reside in the research areas, (ii) What are the local community perception on LVB resources (iii) What are local community perception of the LVB resources degradation levels and causes. Cluster analysis (Norusis, 1990) 
was used to group local communities on the basis of personal characteristics such as age, sex, education, marital status and household composition and also on the basis of resources endowment. Cross tabulation was used to differentiate perceptions by the household characteristics (Bowerman et al., 2011).

Basic statistics including mean, frequency and percentages were computed and used to compare the proportion of responses in each category. Cross tabulation was used to compare the results within and between country sites. Mean values for data collected by Likert Scale questions were computed to obtain the weighted mean (average) for each variable as described by Bowerman et al., (2011) and summarized by Equation (1).

$$
\mathrm{M}_{\mathrm{w}}=\frac{\sum w i x i}{\sum w i}
$$

Where:

$$
\begin{aligned}
& \mathrm{Mw}=\text { Weighted mean for Likert Scale data set on variable } \mathrm{i} \\
& \mathrm{Wi}=\text { Relative frequency of responses in percentage for variable } \mathrm{i} \\
& \mathrm{Xi}=\text { Value of variable } \mathrm{i} \text { in Likert Scale }(1.2,3.4,5)
\end{aligned}
$$

\section{Results and Discussions}

\subsection{Household Characteristics}

\subsubsection{Personal characteristics}

Results on the personal characteristics of community members respondents based on sex, age education levels and length of stay in their place of residents are indicated in Table 1. The results indicate the following:

Sex: Majority (68.5-81.4\%) of respondents were male in all countries, with the highest proportion being in Uganda (81.4\%) and least proportion being in Rwanda (68.5\%). These results don't reflect the actual proportion of female group in the population where it is known that the proportion of female is relatively larger in all countries. However, the results reflect the situation where majority of head of households are male and they are the ones who frequently appear in meetings and influence decision making. These groups are likely to have different perception and knowledge on LVB water resources due to differences in access to resources and

\begin{tabular}{|c|c|c|c|c|c|c|c|}
\hline \multirow{3}{*}{ Characteristics } & \multirow{3}{*}{ Description } & \multicolumn{6}{|c|}{ Responses } \\
\hline & & \multicolumn{2}{|c|}{ Tanzania } & \multicolumn{2}{|c|}{ Uganda } & \multicolumn{2}{|c|}{ Rwanda } \\
\hline & & Freq & $\%$ & Freq & $\%$ & Freq & $\%$ \\
\hline \multirow{2}{*}{ Sex } & Male & 156 & 71 & 48 & 81.4 & 37 & 68.5 \\
\hline & Female & 64 & 29 & 11 & 18.6 & 17 & 31.5 \\
\hline \multirow{4}{*}{ Age (years) } & $<18$ & 2 & 0.9 & 0 & 0 & 2 & 3.7 \\
\hline & $18-35$ & 86 & 38.9 & 23 & 39.6 & 31 & 57.4 \\
\hline & $36-50$ & 96 & 43.4 & 26 & 44.8 & 17 & 31.5 \\
\hline & $>50$ & 37 & 16.7 & 9 & 15.5 & 4 & 7.4 \\
\hline \multirow{4}{*}{$\begin{array}{l}\text { Highest education } \\
\text { level }\end{array}$} & Informal & 10 & 4.7 & 1 & 1.9 & - & - \\
\hline & Primary & 133 & 62.1 & 20 & 37.7 & 7 & 13 \\
\hline & Secondary & 71 & 33.1 & 20 & 37.7 & 31 & 57.4 \\
\hline & Tertiary & & & 12 & 22.6 & 11 & 20.4 \\
\hline \multirow{4}{*}{$\begin{array}{l}\text { Length } \\
\text { (years) }\end{array}$} & $1-4$ & 31 & 16.8 & 3 & 6.3 & 6 & 11.1 \\
\hline & $5-10$ & 37 & 20 & 4 & 8.3 & 2 & 3.7 \\
\hline & $11-15$ & 22 & 10.8 & 2 & 4.2 & 1 & 1.9 \\
\hline & $>15$ & 95 & 51.4 & 39 & 81.3 & 45 & 83.3 \\
\hline
\end{tabular}
information. Normally, women in these countries have limited access due to traditional social barriers although the situation is changing with time (Tenge et al; 2004).

Table 1. Respondents personal characteristics 
Age: Results indicate that relatively large proportion of community members in Tanzania (43.4\%) and Uganda $(44.8 \%)$ were at the age group of $36-50$ years. This implies that they had experience on various issues related to LVB water resources management. Results are slightly different in Rwanda where more than half (57.4\%) of the respondents were young at 18-35 years. Despite the difference in proportions, the two categories are all in reproductive age group though with different experiences. This observation emphasizes the need to use current LVB resources in a sustainable way for the benefits of the current and future generations. These age groups also assure that there is sufficient labour force that can sustainably utilize the LVB water resources if their capacity is enhanced. The relatively small proportion of youths $(<18 \mathrm{yrs})$ in the study areas is explained by the fact that majority at this age are still in Schools and Colleges. These results on age distribution is similar to the findings by Maro (2010) and Kashumba (2010) who observed relatively low proportion of youths in the rural areas of Morogoro and Kagera, Tanzania.

Education level: Results on education levels of community members indicate that majority (62\%) of community members in Tanzania have primary school education while those in Uganda have Secondary (37.7\%) school and tertiary (22.6\%) education. Education levels of respondents from Rwanda are relatively higher than those from the two countries. Results indicate that more than half (57.4\%) had attained secondary school and about quarter (20.4\%) had tertiary education. The different levels of education between the three countries are due to differences in education policies. For instance, in Rwanda secondary school education is free while in Tanzania and Uganda there are elements of cost sharing. Population differences between the three countries can also explain the difference in education levels. However, the levels of education for majority of respondents in the study areas are adequate to understand and manage the LVB resources in sustainable ways. These levels of education need to be considered in developing communication materials for sustainable resources management so that can be understood and used by community members with all levels of education. The results on the levels of education are similar to many other findings that majority of households in rural areas have primary school education (Tenge et al; 2004)

Length of stay in the village: Length of stay in the area has an implication on the experiences on various issues related to the LVB resources. Results in Table 1 indicate that about half $(51 \%)$ of respondents in Tanzania and majority (81.3\%) in Uganda and Rwanda (83.3\%) have stayed in their current place of residence for more than 15 years. This implies that they had adequate experience and knowledge about the issues related to LVB water resources. A relatively large proportion of members who have stayed longer in their respective areas in Uganda and Rwanda may indicate presence of relatively low inflows to the areas. Limited integration may imply adherence to the local values, hence may have different perceptions on the values and management of the LVB water resources.

\subsection{Resources Characteristics}

Resources availability and uses determine the ability and priority of the community in adoption of the technology. Results on the resources available to the communities in the study areas and how they utilize them are presented in Table 2. The results indicate the following;

\subsubsection{Major Economic Activities}

Results (Table 2) indicate that major economic activities in Tanzania and Uganda are crop production, fishing and small business with respective proportions of $47 \% .16 .3 \%$ and $10 \%$ in Tanzania and $47 \%, 13.6 \%$ and $19.7 \%$ in Uganda. The situation is slightly different in Rwanda sites where major economic activities are animal production, formal employment and small businesses. The difference in major economic activities between the three countries is due to the type of production resources that is readily available to each country depending on the location relatively to Lake Victoria water resources. For instance, study sites in Rwanda are relatively far from the lake hence limited or no fishing activities. Major economic activities are likely to influence how the community will value and manage the resources. 
Table 2. Major economic activities in research areas

\begin{tabular}{lccc}
\hline Activity & \multicolumn{3}{c}{ Respondents (\%) } \\
\cline { 2 - 4 } & $\begin{array}{c}\text { Uganda } \\
(\mathrm{n}=59)\end{array}$ & $\begin{array}{c}\text { Rwanda } \\
(\mathrm{n}=54)\end{array}$ & $\begin{array}{c}\text { Tanzania } \\
(\mathrm{n}=221)\end{array}$ \\
\hline Crop production & 47 & 8 & 47 \\
Formal employment & 9.5 & 25 & 14.5 \\
Fishing & 13.6 & 1 & 16.3 \\
Small business & 19.6 & 5 & 10 \\
Wage laborer & 5 & 42 & 4.5 \\
Livestock keeping & 5 & & 7.5 \\
\hline
\end{tabular}

These results further indicate that in all the three countries fishing activities involve less than $15 \%$ of the population in the study areas. These results are different from the common expectation that large proportion of the population living closer to the Lake Victoria is mainly involved in fishing. The results imply that sustainable management of the LVB water resources should not focus only on fishing activities but also to many other activities outside the lake that are taking place and contribute to the degradation of the water resources.

\subsubsection{Assets Ownership and Resource Uses}

Communication facilities: Results in Table 3 indicate that very few community members in each country own computers, internet, modem and fixed telephone lines. Relatively large proportion of community members in all countries own radio and mobile phones. The proportion of the community members who own mobile phones and radio is relatively large in Rwanda (92.8\%) followed by Uganda (66-69.5\%) and Tanzania (48-52\%).

Table 3. ICT facilities

\begin{tabular}{|c|c|c|c|c|c|c|}
\hline \multirow{3}{*}{$\begin{array}{c}\text { Type of } \\
\text { ICT Facilities } \\
\text { Owned }\end{array}$} & \multicolumn{6}{|c|}{ Responses } \\
\hline & \multicolumn{2}{|c|}{ Tanzania } & \multicolumn{2}{|c|}{ Uganda } & \multicolumn{2}{|c|}{ Rwanda } \\
\hline & Freq. & $\%$ & Freq. & $\%$ & Freq. & $\%$ \\
\hline Radio & 108 & 48.9 & 41 & 69.5 & 50 & 92.8 \\
\hline Mobile phones & 115 & 52.0 & 39 & 66.1 & 50 & 92.8 \\
\hline Telephone & 17 & 7.7 & 6 & 10.2 & - & - \\
\hline Television & 29 & 13.1 & 7 & 11.9 & 11 & 20.4 \\
\hline Computer & 6 & 2.7 & 3 & 5.1 & 4 & 7.4 \\
\hline Internet Modem & 6 & 2.7 & 2 & 3.39 & 1 & 1.9 \\
\hline
\end{tabular}

The ownership of television also seems to be relatively higher in Rwanda than in the other two countries. These results have an implication on the accessibility to information and appropriate means to communicate technologies and regulations for sustainable management of LVB resources. All these can have an influence on the knowledge and perception related to water resources in LVB.

Transport facilities: Results (Table 4) indicate that major means of transport that is owned by relatively large proportional of the community members are bicycles. Very few own motor vehicles, motorcycles and boats. Technological options that require transport facilities need to consider availability of these transport facilities. Means of transport can also influence interaction, knowledge and perception on the LVB resources.

Household and energy sources: Results in Table 4 indicate that major energy sources for community members in Tanzania are firewood/charcoal (57.0\%) and Kerosene (47.5\%).

Very few use gas and electricity. Results for Uganda indicated that the major energy sources are Kerosene $(57.6 \%)$ and firewood/charcoal $(30.5 \%)$. Major energy sources for community members in Rwanda are firewood/charcoal $(64.8 \%)$ and gas $(42.6 \%)$. The use of firewood and charcoal by relatively large proportion of 
the community members may be among the factors contributing to the degradation of the LVB water resources. Mitigation measures and management of LVB water resources need to consider promotion of alternative energy sources. The observation that relatively large proportion of community members in Rwanda is using gas need to be shared and promoted in other countries. Efforts to ensure sustainable utilization of LVB water resources without alternative energy sources may not be fruitful.

Table 4. Transport and energy sources

\begin{tabular}{clcccccc}
\hline \multirow{2}{*}{$\begin{array}{c}\text { Type of facility } \\
\text { owned }\end{array}$} & Description & \multicolumn{5}{c}{ Responses } \\
\cline { 3 - 7 } & & \multicolumn{2}{c}{ Tanzania } & \multicolumn{2}{c}{ Uganda } & \multicolumn{2}{c}{ Rwanda } \\
\cline { 3 - 7 } & & Freq. & $\mathbf{\%}$ & Freq. & $\mathbf{\%}$ & Freq. & $\%$ \\
\hline \multirow{2}{*}{ Transport } & Bicycle & 72 & 32.6 & 26 & 44.1 & 22 & 40.7 \\
& Motor cycle & 10 & 4.5 & 4 & 6.8 & 3 & 5.6 \\
& Motor vehicle & 4 & 1.8 & 4 & 6.8 & 3 & 5.6 \\
& Boat & 11 & 5.0 & 8 & 13.6 & 1 & 1.9 \\
& Grid Electricity & 16 & 7.2 & 9 & 15.3 & 7 & 13. \\
& Solar Electricity & 20 & 9.0 & 2 & 3.4 & 4 & 7.4 \\
& Firewood/charcoal & 126 & 57.0 & 18 & 30.5 & 35 & 64.8 \\
& Kerosene & 105 & 47.5 & 34 & 57.6 & 30 & 55.6 \\
& Gas & 19 & 8.6 & - & - & 23 & 42.6 \\
\hline
\end{tabular}

\subsection{Perception on Lake Victoria Basin Water Resources}

Perception of benefits from the LVB may influence community on the value and importance of sustainable utilization of the resources. Results in Table 5 show community member's awareness and perception on the benefits from the LVB water resources.

Table 5. Community members' awareness and perceptions on the benefits of LVB water resources

\begin{tabular}{lllllll}
\hline \multirow{2}{*}{ Benefits } & \multicolumn{7}{c}{ Responses } \\
\cline { 2 - 7 } & $\begin{array}{l}\text { Tanzania } \\
\text { Freq. }\end{array}$ & $\boldsymbol{\%}$ & Freq. & $\%$ & Freq. & $\%$ \\
\hline Income generation & 96 & 43.4 & 17 & 28.8 & 24 & 44.5 \\
Food source & 95 & 43.0 & 17 & 28.8 & 21 & 39 \\
Water supply & 70 & 31.7 & 13 & 22.0 & 25 & 46.3 \\
Tourism & 6 & 2.79 & 5 & 8.5 & - & - \\
Transport & 14 & 6.3 & - & - & 23 & 42.6 \\
Construction sand & - & - & 3 & 5.1 & - & - \\
Timber & - & - & 2 & 3.4 & - & - \\
Irrigation & 34 & 15.4 & 1 & 1.7 & 30 & 55.6 \\
Weather & 1 & 0.5 & 6 & 10.2 & & 3.7 \\
Source of energy & 03 & 1.4 & - & - & 2 & \\
Research/Training & & & 2 & 2.5 & & \\
\hline
\end{tabular}

The results indicate that the most perceived benefits are income generation, food supply, water supply and weather modification. Most perceived benefits in Tanzania in order of importance are income generation (43.4\%), food source (43.0\%) and water supply (31.7\%). 
Similar perception is observed for community members in Uganda at proportions of $28.8 \%$ for income generation, $28.8 \%$ food source and $22 \%$ water supply. The order of importance is different in Rwanda where irrigation is leading (55.6\%) followed by navigation (46.6\%) and income generation (44.5\%). The differences in order of importance reflect the differences in awareness and accessibility of LVB water resources among the three countries. Other benefits perceived at different levels are construction materials (sand and timber) sources of energy for cooking and research activities. There is interaction of some benefits. These perceived benefits reflect what the community expects from the LVB resources and have consequences on the perception and activities undertaken to realize the benefits. However, it should be noted that respondents in this case were referring to LVB resources rather than Lake Victoria water resources alone.

\subsection{Perception on LVB Resources Degradation}

Community perceptions on resources degradation determine the knowledge, concern and altitudes towards the mitigation and adaptation measures. In this research community members' perception on the levels of degradation of the LVB water resources was assessed based on the parameters of quality and quantity of water, fish and forest cover. The overall perception for the resource parameter was evaluated based on the weighted mean score from the Likert Scale questions and percentage of respondents in the parameter. Results in Table 6, indicate that community members in Tanzania are observing a declining trend (-1) for all parameter with exception of the water quality which is perceived to be constant $(0)$ and ambient temperature which is perceived to be increasing. Community perception that water quality has not changed is different from available scientific evidences.

Table 6. Local community perception on status of LVB resources in Tanzania

\begin{tabular}{lccc}
\hline Indicator/parameter & \multicolumn{3}{c}{ Resource Status (Score) } \\
\cline { 2 - 4 } & $\mathrm{W}_{\mathrm{c}} X$ & $\mathrm{~W}_{\mathrm{p}} X$ & $\Delta X$ \\
\hline Water quality & 2 & 2 & 0 \\
Water quantity & 2 & 3 & -1 \\
Quantity of fish & 2 & 3 & -1 \\
Species of fish & 2 & 3 & -1 \\
Ambient Temperature & 3 & 2 & 1 \\
Rainfall quantity & 2 & 3 & -1 \\
Catchment's forest cover & 2 & 3 & -1 \\
\hline
\end{tabular}

$\mathrm{W}_{\mathrm{c}} X$ = weighted mean score for current status; $\mathrm{W}_{\mathrm{p}} X=$ weighted mean score for the past; $\Delta X=$ Change

Scale: $\operatorname{High}(\mathrm{H})=3$; Moderate $(\mathrm{M})=2 ;$ Low $(\mathrm{L})=1$

This can be explained by the difficulty at the community level to measure or assess the water quality.

These results imply that water quality may not be a good indicator to convince the community that LVB resources are degraded. Results from Uganda (Table 7) indicate that with exception of ambient temperature which are perceived not to have undergone significant changes ( 0$)$; all other indicators are perceived to have a declining trend (-1). 
Table 7. Local community perception on status of LVB resources in Uganda

\begin{tabular}{lccc}
\hline Indicator/parameter & \multicolumn{3}{c}{ Resource Status (Score) } \\
\cline { 2 - 4 } & $\mathrm{W}_{\mathrm{c}} X$ & $\mathrm{~W}_{\mathrm{p}} X$ & $\Delta X$ \\
\hline Water quality & 2 & 3 & -1 \\
Water quantity & 2 & 3 & -1 \\
Quantity of fish & 2 & 3 & -1 \\
Species of fish & 2 & 3 & -1 \\
Ambient Temperature & 2 & 2 & 0 \\
Rainfall quantity & 2 & 3 & -1 \\
Catchment's forest cover & 2 & 3 & -1
\end{tabular}

$\mathrm{W}_{\mathrm{c}} \bar{X}=$ weighted mean score for current status; $\mathrm{W}_{\mathrm{p}} \bar{X}=$ weighted mean score for the past; $\Delta X=$ Change

Scale: $\operatorname{High}(\mathrm{H})=3$; Moderate $(\mathrm{M})=2 ;$ Low $(\mathrm{L})=1$

Results from Rwanda (Table 8) indicate that with exception of the ambient temperature which is perceived to be increasing, community members perceive no significant change in the LVB resource parameters for the past twenty years. Discussion with respondents and key informants revealed that the situation was due to afforestation campaigns undertaken in Rwanda and also due to seriousness in enforcing and adhering to the laws that govern LVB resources. Distance to LVB water resources could also explain the results.

Table 8. Local community perception on status of LVB resources in Rwanda

\begin{tabular}{lccc}
\hline Indicator/parameter & \multicolumn{3}{c}{ Resource Status (Score) } \\
\cline { 2 - 4 } & $\mathrm{W}_{\mathrm{c}} X$ & $\mathrm{~W}_{\mathrm{p}} X$ & $\Delta X$ \\
\hline Water quality & 2 & 2 & 0 \\
Water quantity & 2 & 2 & 0 \\
Quantity of fish & 2 & 2 & 0 \\
Species of fish & 2 & 2 & 1 \\
Ambient Temperature & 3 & 2 & 0 \\
Rainfall quantity & 2 & 2 & 0 \\
Catchment's forest cover & 2 & 2 & 0 \\
\hline
\end{tabular}

$\mathrm{W}_{\mathrm{c}} \bar{X}=$ weighted mean score for current status; $\mathrm{W}_{\mathrm{p}} \bar{X}=$ weighted mean score for the past; $\Delta X=$ Change

Scale: High $(\mathrm{H})=3$; Moderate $(\mathrm{M})=2$; Low $(\mathrm{L})=1$

\subsection{Community Perception on the Causes of LVB Resources Degradation}

Community members explained reasons for the observed trend of degradation of LVB resources. These reasons were weighted to indicate the relative importance or seriousness of each cause based on the number of times each was mentioned by the respondents (Table 9). 
Table 9. Community perception on the causes of LVB resources degradation

\begin{tabular}{lccc}
\hline Cause & \multicolumn{3}{c}{ Weights } \\
\cline { 2 - 4 } & Tanzania & Uganda & Rwanda \\
\hline Water pollution & 0.19 & 0.06 & 0.15 \\
Climate Change & 0.23 & 0.14 & 0.15 \\
Deforestation & 0.06 & 0.19 & 0.06 \\
Population pressure & 0.00 & 0.14 & 0.09 \\
Over-fishing & 0.10 & 0.06 & 0.09 \\
Illegal fishing methods & 0.10 & 0.08 & 0.06 \\
Exotic fishes & 0.06 & 0.06 & 0.09 \\
Water weeds & 0.10 & 0.03 & 0.09 \\
Waste disposal & 0.06 & 0.03 & 0.03 \\
Poor leadership & 0.03 & 0.08 & 0.03 \\
Poor farming methods & 0.03 & 0.06 & 0.03 \\
Industrial pollution & 0.03 & 0.08 & 0.06 \\
Siltation & 0.00 & 0.00 & 0.06 \\
\hline Total & 1 & 1 & 1 \\
\hline
\end{tabular}

Results indicate that respondents from Tanzania perceived climate change (0.23), water pollution (0.19), overfishing (0.10), illegal fishing $(0.10)$ and water weeds $(0.10)$ as the major reasons for the degradation of LVB resources. Respondents from Tanzania did not consider population pressure and siltation as major reasons for the degradation trend of LVB resources. This could be due to the relatively large size of the country. Perceived major reasons for resource degradation in Uganda included deforestation (0.19), climate change (0.14) and population pressure (0.14). Perceived reasons by community members in Rwanda included water pollution (0.15), climate change (0.15), population pressure (0.09), overfishing (0.09), illegal fishing (0.09 and exotic fish (0.09)

Results indicate that perceptions of the local communities in terms of causes of LVB resource degradation do not differ between the study sites. The only difference observed is the perception on the seriousness of each cause. Reasons perceived by the local community also do not differ from reasons identified by scientific research. However, community members could not clearly distinguish the causes and effects. These results provide a good framework for enhancing community capacity to address the LVB resources degradation problems.

Generally the results indicate that the reasons apply across all countries. The reasons range from technical, policy, administrative and personal factors. These observations imply that mitigation/intervention measures should be of multiple responses to address all factors.

\section{Conclusions}

Based on the findings from this research the following conclusion can be reached.

Majority of households surrounding the LVB are male headed, middle aged with primary school education level. These characteristics imply that, interventions for sustainable utilization of LVB resources should not target head of households only otherwise they will miss majority of female who are not head of households. Interventions also need to use simple language and means of communication that can be understood by majority of community members with primary school education. Major economic activities are crop farming, formal employment, fishing and livestock keeping. Interaction of these economic activities and personal characteristics contribute to the LVB resources degradation.

Much dependence on fuel wood as the major source of energy is contributing to the LVB degradation due to deforestation. This is compounded by the population pressure and lack of affordable alternative sources.

Local community perceives that LVB resources are currently more degraded compared to the past twenty years. However, the degradation indicators do differ from one country to another. Ambient temperature is a common indicator of changes in all countries. Local community members are aware of all possible cause of degradation but can't distinguish between the causes and effects. 
Local community member's awareness on levels of resources degradation and causes is a good starting point for interventions to ensure sustainable utilization of LVB water resources.

It is recommended that efforts to address LVB resources degradation should consider and include local community perceptions, alternative livelihood options and be integrative of technical, policy and administratively options.

\section{Acknowledgement}

The research reported in this paper was conducted as part of the project on ICT and Adaptation to Climate Change: Innovative and Integrated Solutions to Address Challenges of Water Resources Governance within Lake Victoria Basin

Authors are grateful to Lake Victoria Research Initiative (VICRES), Inter-University Council of East Africa (IUCEA) and Swedish Development Agency (SIDA) for providing funds to carry out this research. They would like to thank the VICRES coordinator for the support during this research. The input of respondents and key informants in all study sites is highly acknowledged.

\section{References}

Agrawal, A., \& Gibson, C. (1999). Enchantment and Disenchantment: The role of Community in Natural $\begin{array}{lllll}\text { Resources } \quad \text { Conservation. } & \text { World }\end{array}$ http://dx.doi.org/10.1016/S0305-750X(98)00161-2

Bagheri, A., Shabanali Fami, H., Rezvanfar, A., Asadi, A., \& Yazdani, S. (2008). Perceptions of Paddy Farmers Towards Sustainable Agricultural Technologies: Case of Haraz Catchments Area in Mazandaran Province of Iran. American Journal of Applied Sciences, 5(10), 1384-1391. http://dx.doi.org/10.3844/ajassp.2008.1384.1391

Berkes, F. (2004). Rethinking Community Based Conservation. Conservation Biology, 18(3) 621-630. http://dx.doi.org/10.1111/j.1523-1739.2004.00077.x

Bowerman, L., O’Connell, R., \& Murphree, E. (2011). Business Statistics in Practice (6th ed.). MacGraw- Hill, New York.

Bryman, A. (2001). Social Research Methods. Oxford University Press.

Bryman, A., \& Cramer, D. (1992). Quantitative Data Analysis for Social Scientists. Routledge, London.

Chamber, R. (1987). Sustainable Rural Livelihoods: A Strategy for People Environment and Development. Institute of Development Studies. University of Sussex, Brighton.

Churchill, G. (1979). A Paradim for Developing Better Measures of Marketing Constructs. Journal of Marketing Research, 16(February), 64-73. http://dx.doi.org/10.2307/3150876

Cox, M., Arnold, G., \& Villamaytonias, S. (2010). A review of Design Principles for Community -Based Natural Resource Management. Ecology and Society, 15(4), 38.

Cramb, R. A. (2003). Processes affecting the successful adoption of new technologies by smallholder. In B. Hacker (Ed.), Working with farmers: The key to adoption of forage technologies (pp. 11-22). ACIAR Proceedings No. 95. Canberra: Australian Centre for International Agricultural Research.

D’Souza, G., Cyphers, D., \& Phipps, T. (1993). Factors affecting the adoption sustainable agricultural Practices. Agricultural and Resources Economics Review, 159-165.

De Graaff, J., Amsalu, A., Bodner, F., Kessler, A., Posthumus, H., \& Tenge, A. J. (2008). Factors influencing adoption and continued use of long-term soil and water conservation measures in five developing countries. Applied Geography, 28, 271-280. http://dx.doi.org/10.1016/j.apgeog.2008.05.001

DeGeorges, P. A., \& Reilly, B. K. (2009). The Realities of Community Based Natural Resource Management and Biodiversity Conservation in Sub-Saharan Africa. Sustainability, (1), 734-788. http://dx.doi.org/10.3390/su1030734

Devore, J., \& Peak, R. (1993). Statistics: The Exploration and Analysis of Data. Duxbury Press, California.

Field, A. (2005). Discovering Statistics using SPSS (2nd ed.). SAGE Publications. London.

Goman, M. C., Mahay, F., Mbilinyi, B., Dietrich, O., \& Lischeid, G. (2009). Establishment of Hydrological Monitoring System through a Participatory Approach in Small Tropical Catchment in Tanzania: Learning Hydrology from Local People. Conference on International Research on Food Security, Natural 
Management and Rural Development. University of Hamberg, October 6-8, 2009. Retrieved from http://www.tropentag.de/2009/abstracts/full/584.pdf. 02.01.2015.

Gordon, H. S. (1954). The economic theory of a common-property resource: The fishery. Journal of Political Economy, 62(2), 124-142. http://dx.doi.org/10.1086/257497

Hardin, G. (1968). The Tragedy of Commons. Science, 162(3859), 1243-1248. http://dx.doi.org/10.1126/science.162.3859.1243

Inter-governmental Panel on Climate Change. (IPCC), (2001). Climate Change: Impacts, Adaptation and Vulnerability, Contribution of the Working group II to the Third Assessment Report of IPCC. IPCC. Retrieved July 4, 2010, from http://www.ipcc.ch

Kashumba, F. (2010). Factors influencing choice of unemployment coping strategies among the rural youth in Tanzania: The case of Muleba district, Kagera region. (Unpublished MA Dissertation), University of Dodoma, Tanzania.

Knowler, D., \& Bradshaw, B. (2007). Farmers' adoption of conservation agriculture: A review and synthesis of recent research. Food Policy, 32, 25-48. http://dx.doi.org/10.1016/j.foodpol.2006.01.003

Lake Victoria Basin Commission (LVBC). (2010). About LVBC. Retrieved June 13, 2010, from http://www.lvbcom.org

Lancaster, G. (2005). Research Methods in Management: A Concise Introduction to Research in Management and Business Consultancy. Elsevier Butterworth-Heineman, Burlington. Retrieved March 1, 2015, from http://www.books.elservier.com

Lundstrom, W. J., \& Lamont, L. M. (1976). Development of a Scale to Measure Consumer Discount. Journal of Marketing Research, 13(11), 373-381. http://dx.doi.org/10.2307/3151020

Maro, F. (2010). Social and economic factors that influence youth disengagement in agriculture in Morogoro, Tanzania. Unpublished MA Dissertation), University of Dodoma, Tanzania.

Norusis, M. J. (1990). Statistical Package for Social Sciences [SPSS]: Advanced Statistical Guide. SPSS International BV. Gronchem.

Roe, D., Nelson, F., \& Sandbook, C. (2009). Community Management of Natural Resources in Africa: Impacts, Experiences and Future Directions. Natural Resource Issues No. 18, International Institute for Environmental and Development. London.

Shacleton, S., Campbell, B., Wollenberg, E., \& Edmund, D. (2002). Devolution and Community- Based Natural Resources Management: Creating Space for Local people to Participate and Benefit?. ODI, Natural Resources Perceptions, DFID

Tenge, A. J., De Graaff, J., \& Hella, J. P. (2004). Social and Economic Factors Affecting the Adoption of Soil and Water Conservation in West Usambara Highlands, Tanzania. Land Degradation and Development, 15, 99-114. http://dx.doi.org/10.1002/ldr.606

Van de Walle, N. (2001). African Economics and Politics of Permanent Crisis, 1979-1999. Cambridge, University Press. http://dx.doi.org/10.1017/CBO9780511800344

Wood, L. (2008). Community-Based Natural Resource Management: Case Studies from Community Forest Management Projects in Ghana, Mexico and United States of America. NRES 525. International Resource Management.

\section{Copyrights}

Copyright for this article is retained by the author(s), with first publication rights granted to the journal.

This is an open-access article distributed under the terms and conditions of the Creative Commons Attribution license (http://creativecommons.org/licenses/by/3.0/). 